\title{
Novel Method for Optimal Synthesis of 5G Millimeter Wave Linear Antenna Array
}

\author{
Zarko Rosic, ${ }^{1}$ Olivera Mihic, ${ }^{1}$ Danijela Aleksic, ${ }^{2}$ and Dejan Drajic ${ }^{3}$ \\ ${ }^{1}$ Faculty of Organizational Sciences, University of Belgrade, Jove Ilića 153, 11000 Belgrade, Serbia \\ ${ }^{2}$ Faculty of Technical Sciences, University of Kragujevac, Svetog Save 55, 32000 Cacak, Serbia \\ ${ }^{3}$ Faculty of Electrical Engineering, University of Belgrade, Bulevar Kralja Aleksandra 73, 11000 Belgrade, Serbia
}

Correspondence should be addressed to Zarko Rosic; zarko.rosic88@gmail.com

Received 10 December 2016; Accepted 5 February 2017; Published 13 March 2017

Academic Editor: Stefan R. Panic

Copyright (C) 2017 Zarko Rosic et al. This is an open access article distributed under the Creative Commons Attribution License, which permits unrestricted use, distribution, and reproduction in any medium, provided the original work is properly cited.

\begin{abstract}
We will propose a useful method for $5 \mathrm{G}$ mm wave antenna array synthesis, based on Genetic Algorithm for the synthesis of linear array with nonuniform interelement spacing. Our design method was used to obtain the optimal position of the elements in order to get the minimum side lobe level and nulls in desired directions. The simulation results verify that proposed method outperforms the previously published methods in terms of suppression side lobe level while maintaining nulls in specified directions. The flexibility of proposed algorithm shows good potential for the antenna array synthesis.
\end{abstract}

\section{Introduction}

In order to satisfy necessary $5 \mathrm{G}$ quality-of-standard criteria and meet user mobility, due to the higher path loss at $\mathrm{mm}$ wave frequency range, multiple antenna arrays are typically used in outdoor mm wave systems for providing additional gain $[1,2]$. They play an important role in detecting and processing signals arriving from different directions. The performance of the systems depends on the efficient design of the antenna arrays. The desired radiation pattern can be realized by choosing geometrical shape of antenna array, element excitation amplitude, element excitation phase, and element spacing. The objectives in design of the antenna arrays are archiving minimum side lobe level (SLL) and narrow first null beam width (FNBW). Interference issues will become of crucial importance for coexistence of 5G devices, since number of $\mathrm{mm}$ wave devices will grow extensively in near future [3]. The increasing growth of $5 \mathrm{G}$ devices number will prompt the study of array pattern nulling techniques. This problem will reach its culmination in future dense $\mathrm{mm}$ wave application, such as for the $60 \mathrm{GHz}$ dense indoor communication, and various outdoor $\mathrm{mm}$ wave $5 \mathrm{G}$ communication in densely populated urban areas [4]. So the goal of antenna array synthesis is to achieve the minimum SLL with narrow
FNBW and obtaining narrow or broad nulls in directions of interfering signals. The broad nulls are needed when the direction of arrival of interference may vary slightly with time.

For the linear array geometry, by optimizing the spacing between the elements while keeping the uniform excitation we can suppress side lobe level while preserving the gain of the main beam and can control nulling.

Methods used for the antenna array synthesis can be classified in two categories: deterministic and stochastic. There are several deterministic methods: Schelkunoff Polynomial Method [5], Dolph-Chebyshev Method [6, 7], WoodwardLawson Method $[8,9]$, and Fourier Transform Method [6, $8,9]$. In modern research the most common methods are stochastic, because stochastic methods can almost all be proven to find a global minimum with asymptotic convergence in probability. The biggest advantages of using stochastic methods are their ability in dealing with large number of optimization parameters and avoiding getting stuck in local minima. Some of the methods used for the antenna array synthesis are Evolutionary Algorithms (EA) [10], Genetic Algorithms (GA) [11-13], Tabu Search (TS) [11, 14], Particle Swarm Optimization (PSO) [15-17], Ant Colony Optimization (ACO) [18], Nature-Inspired Cuckoo Search 


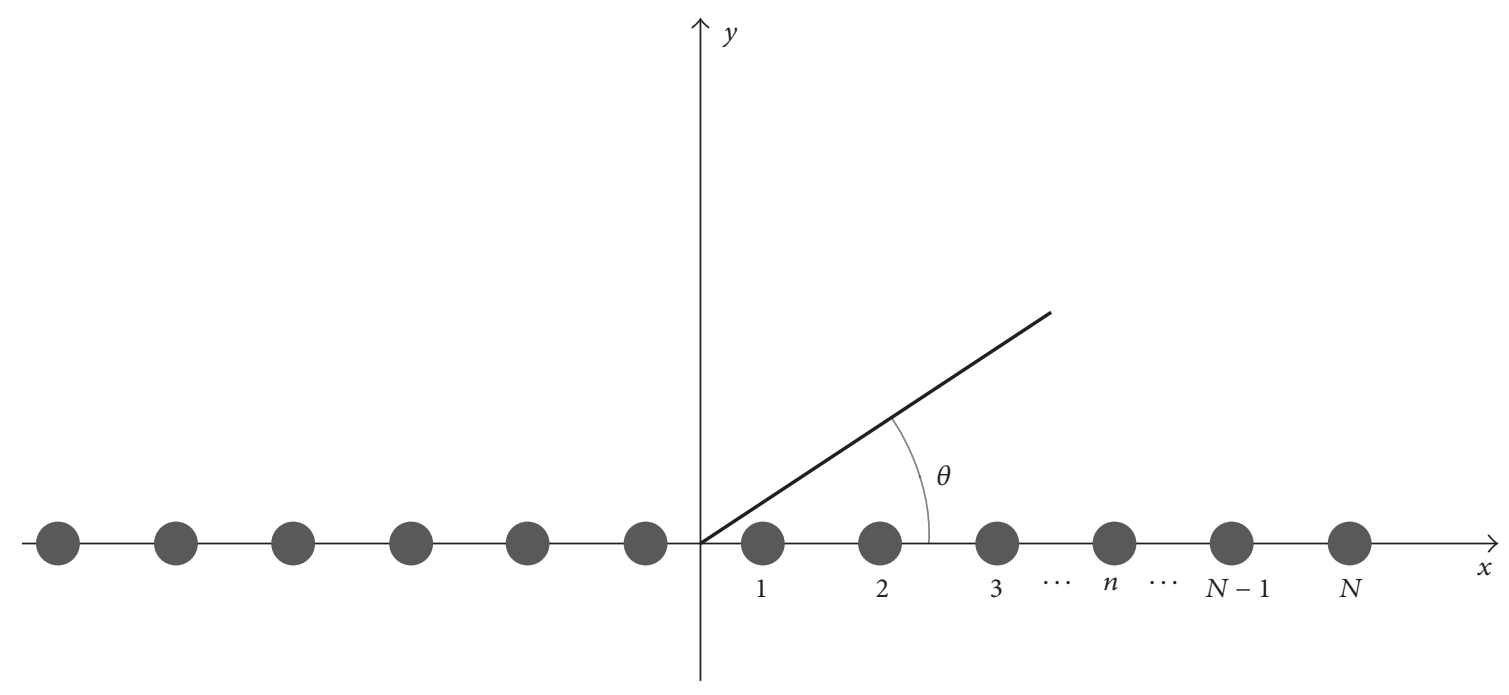

FIGURE 1: Geometry of $2 \mathrm{~N}$-element linear antenna array.

(CS) $[19,20]$, Combination of Global and Local Search [21], and Cat Swarm Optimization [22]. All the above-mentioned methods have shown the capability of searching for global solution in electromagnetic optimization problems.

In this paper, we proposed a useful method based on combination of two global searches. The main idea comes from method based on combination of global and local search [21]. Changing local search into global search we avoid getting stuck in local minimum and this leads to better exploration of feasible region. Better exploration leads to better solution of optimization problem. Presented algorithm was used to obtain the optimal position of the elements in order to get the minimum side lobe level and nulls in desired directions. We applied for optimization the same radiation pattern requirements of the selected papers. The simulation results reveal that design of antenna arrays using the presented method provides considerable enhancements compared with the synthesis obtained from other published methods. In this approach we will concern arrays of isotropic point sources; this is of great value because the pattern of any antenna can be regarded as being produced by an array of point sources.

Description of antenna array design problem is given in Section 2. In Section 3, a description of the used algorithm is presented. Results are presented in Section 4. Finally, the conclusion of this work is presented in Section 5.

\section{Problem Formulation}

The antenna array radiation pattern (RP) may be found according to the pattern multiplication theorem (see, e.g., Ch. 6 from [6, 24] and Ch. 3 from [25]):

$$
\mathrm{RP}=\mathrm{EL} \cdot \mathrm{AF} .
$$

EL (element pattern) is the pattern of the individual array element.
AF (array factor) is a function dependent on the physical placement of antenna elements, amplitude, and phase of excitation.

If we replace each element of the antenna array with an isotopic point source the resulting pattern is the array factor, because the element pattern of isotopic point source is equal to 1 . The geometry of the linear antenna array with $2 N$ isotropic elements placed symmetrically along the $x$-axis is given in Figure 1.

In this paper linear antenna array has identical elements with nonuniform interelement spacing and uniform excitation. Array factor in the azimuth plane can be expressed as follows (for more see [6, 8, 9, 24-26]):

$$
\operatorname{AF}(\theta)=2 \sum_{n=1}^{N} I_{n} \cos \left[k d_{n} \sin (\theta)+\varphi_{n}\right]
$$

where $k=2 \pi / \lambda$ is wave number, $\lambda$ is the wavelength, $I_{n}$ is excitation amplitude of $n$th element, $\varphi_{n}$ is excitation phase of $n$th element, $d_{n}$ is location of $n$th element, and $\theta$ is angle between the line of observer and the source position.

If we assume a uniform excitation of phase as $\varphi_{n}=0$ for each antenna array element, the array factor can be written in a simple form as follows:

$$
\operatorname{AF}(\theta)=2 \sum_{n=1}^{N} I_{n} \cos \left[k d_{n} \sin (\theta)\right]
$$

In the field of electromagnetism the decibel $(\mathrm{dB})$ is often used as a unit of measurement for array factor. Normalized array factor and normalized array factor in $\mathrm{dB}$ are given by

$$
\begin{aligned}
(\operatorname{AF}(\theta))_{\text {norm }} & =\frac{|\operatorname{AF}(\theta)|}{|\max (\operatorname{AF}(\theta))|} \\
(\operatorname{AF}(\theta))_{\text {norm,db }} & =20 \log \frac{|\operatorname{AF}(\theta)|}{|\max (\operatorname{AF}(\theta))|} .
\end{aligned}
$$




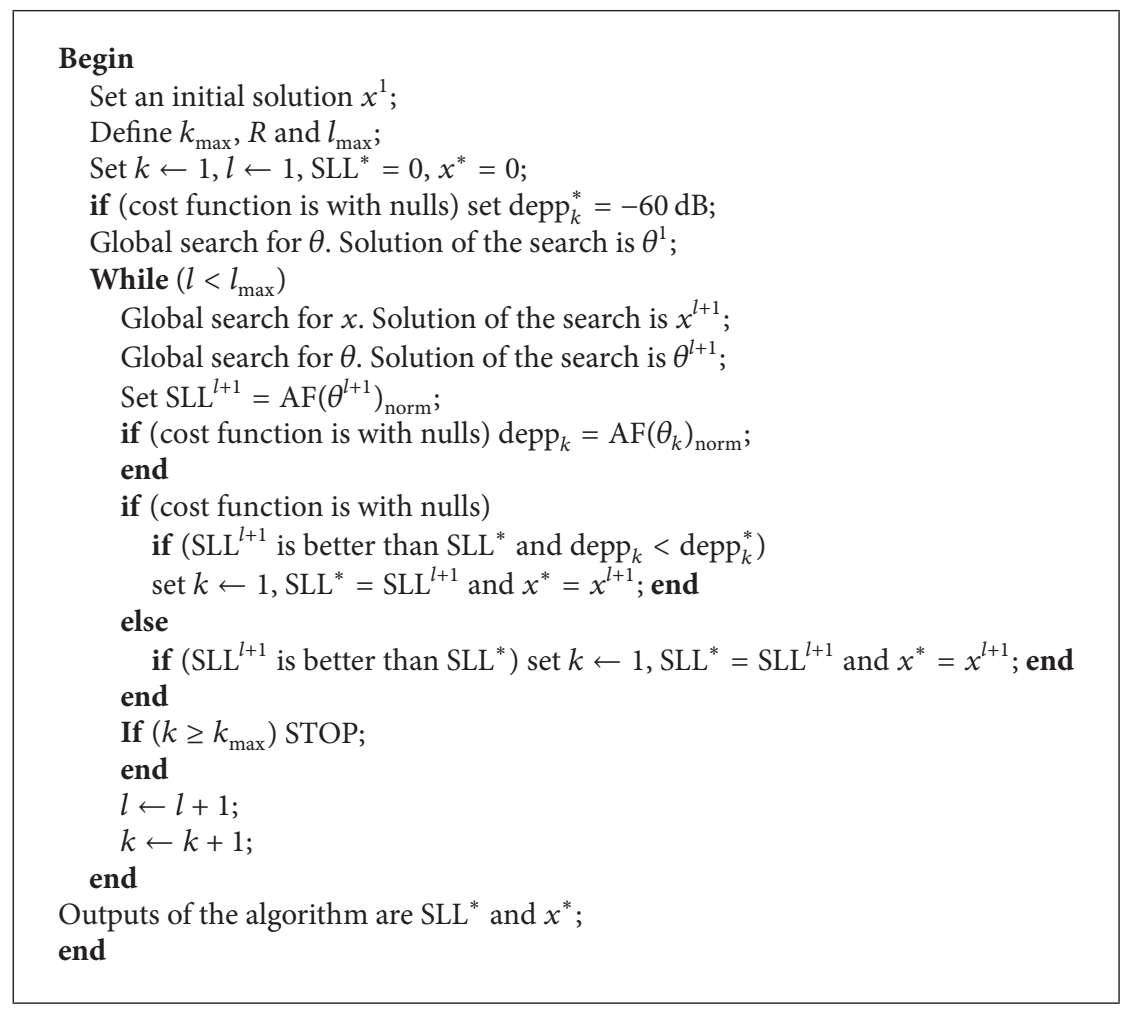

Algorithm 1

\section{Algorithm}

The presented algorithm is applied to achieve the desired radiation pattern with minimum SLL and narrow or broad nulls in specified directions. Our approach uses a combination of two global searches: global search with respect to $\theta$ and global search with respect to $x$. The global searches were performed using Genetic Algorithm with existing function "ga" from MATLAB software package (R2016a). The global search with respect to $\theta$ was performed on region $\left[\theta_{11}, \theta_{12}\right]$ with fixed permanent solution $x^{l}$ for the cost function (4). With this global search we locate maximum side lobe level.

The cost function for step global search for $x$ following expression was used:

$$
\text { Cost }=\max \left(\left.\operatorname{AF}(\theta)_{\text {norm }}\right|_{\theta_{11}} ^{\theta_{12}}\right)+\sum_{k} \operatorname{AF}\left(\theta_{k}\right)_{\text {norm }} \cdot
$$

First term in (6) is employed to minimize the side lobe level between the desired angles $\theta_{11}$ and $\theta_{12}$, whereas the second one is for achieving deep nulls in desired directions $\theta_{k}$. For reducing mutual coupling effects between the elements of the antenna array the following conditions must be satisfied:

$$
\begin{aligned}
& \left|x_{i}-x_{j}\right|>0.25 \lambda, \\
& \min \left(x_{i}\right)>0.125 \lambda, \quad i=1,2, \ldots, N, i \neq j .
\end{aligned}
$$

The global search with respect to $x$ on a small neighbourhood of current solution was performed with fixed $\theta^{l}$. Lower and upper bounds for each coordinate of vector $x^{l}$ are defined using the following expression:

$$
\begin{aligned}
\mathrm{LOW}_{i} & =\left(x_{i}^{l}-R\right), \quad i \in N, R \in \mathfrak{R}, \\
\mathrm{UP}_{i} & =\left(x_{i}^{l}+R\right), \quad i \in N, R \in \mathfrak{R} .
\end{aligned}
$$

Pseudocode of proposed algorithm is given in Algorithm 1 .

\section{Simulation Results}

In the first experiment we performed the synthesis of $2 \mathrm{~N}=$ 28 element antenna array in order to get the minimum side lobe level and nulls at $\theta_{1}=30^{\circ}, \theta_{2}=32.5^{\circ}$, and, $\theta_{3}=35^{\circ}$. In this paper we performed experiments for $R=0.05$ and 0.1 (with respect to $\lambda / 2$ ) where $\theta_{11}=4^{\circ}$ and $\theta_{12}=90^{\circ}$.

The cost function for the algorithm following expression was used:

$$
\text { Cost }=\max \left(\left.\operatorname{AF}(\theta)_{\text {norm }}\right|_{4^{\circ}} ^{90^{\circ}}\right)+\sum_{k} \operatorname{AF}\left(\theta_{k}\right)_{\text {norm }} .
$$

We can see that in this paper cost function is not same as that in paper [23]. The main reason why the form of the cost function (9) was taken, rather than form (10), is that the value of the second part of cost function tends towards negative infinity for $\operatorname{AF}\left(\theta_{k}\right)_{\text {norm }}=0$. This case would adversely affect the search in such a way that the search for the second part of (10) would be predominant. In this case, we took normalized 

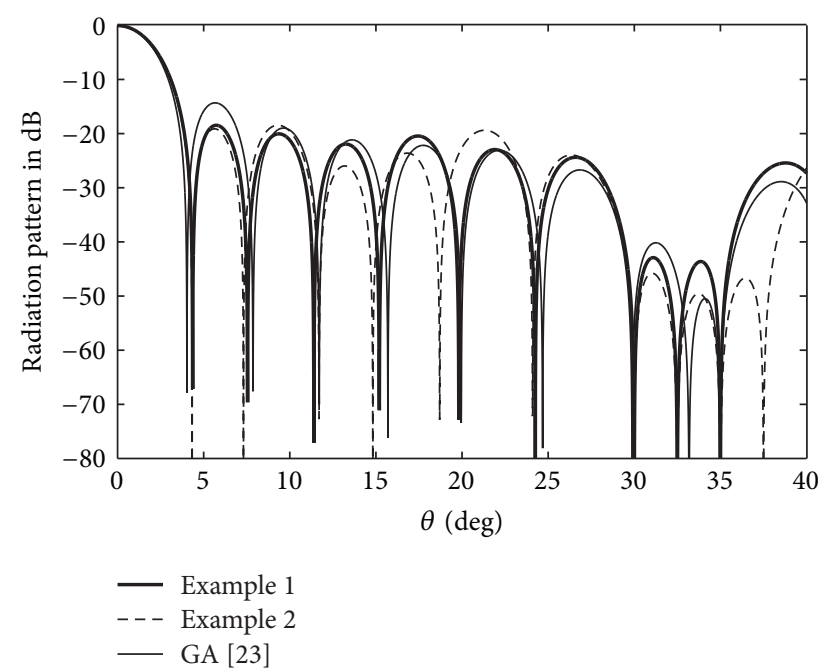

Figure 2: The normalized radiation pattern of 28-element linear array.

array factor and therefore it is unlikely that such a case could occur.

$$
\begin{aligned}
\text { Cost }= & 20 \log \left\{\max \left(\left.\operatorname{AF}(\theta)_{\text {norm }}\right|_{4^{\circ}} ^{90^{\circ}}\right)\right\} \\
& +20 \log \left\{\sum_{k} \operatorname{AF}\left(\theta_{k}\right)_{\text {norm }}\right\} .
\end{aligned}
$$

The radiation pattern has been shown in Figure 2. As it is seen from Figure 2 obtained results give lower side lobe level then results from paper [23]. Region $\left[30^{\circ}, 35^{\circ}\right]$ is under $-40 \mathrm{~dB}$ and it is lower than obtained region from published work. The optimal locations with respect to $\lambda$ obtained by using the provided algorithm are shown in Table 1 . In Table 2 SLL, FNBW, and nulls depth at $\theta_{1}=30^{\circ}, \theta_{2}=32.5^{\circ}$, and $\theta_{3}=35^{\circ}$ are shown. Convergence characteristics in terms of side lobe level versus the number of iterations are shown in Figure 3. It is observed that the cost function value converges to the optimum result quickly.

The observed results were better for $R=0.05$. From Table 2, it is seen that the results provide side lobe level lower than $-18 \mathrm{~dB}$, with nulls deeper than $-100 \mathrm{~dB}$. Minimum side lobe level of the array optimized using presented algorithm showed improvement $(4 \mathrm{~dB})$ over the published works GPS [23], ACO [18], and CSO [22] (Table 3). All three nulls are deeper than $-100 \mathrm{~dB}$ and all nulls are deeper than nulls from published works. The FNBW is slightly higher than previously published works.

In the second experiment, we performed the synthesis of $2 N=20$ elements' antenna array with fixed excitation Dolph-Chebyshev amplitudes, which form the side lobe level at $-30 \mathrm{~dB}$. Excitation amplitudes have values $=[1,0.97,0.912$, $0.831,0.731,0.620,0.504,0.391,0.285,0.325]$. Null is located at the position of $\theta_{1}=20^{\circ}$, whereas $\theta_{11}=8^{\circ}$ and $\theta_{12}=90^{\circ}$.

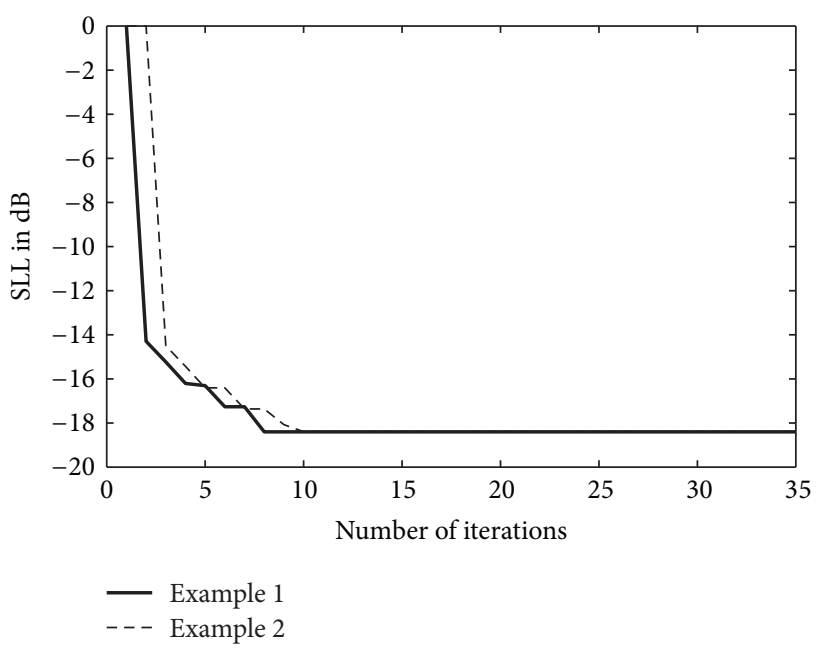

Figure 3: The convergence characteristics of side lobe level for optimization of a 28-element linear array.

TABLE 1: Element position of the 28-element linear array (normalized with respect to $\lambda$ ).

\begin{tabular}{lccc}
\hline Element & Example 1 $(R=0.05)$ & Example 2 $(R=0.1)$ & GA [23] \\
\hline \pm 1 & 0.1901 & 0.2081 & 0.252 \\
\pm 2 & 0.6309 & 0.6048 & 0.752 \\
\pm 3 & 1.0720 & 1.0688 & 1.251 \\
\pm 4 & 1.5273 & 1.4997 & 1.754 \\
\pm 5 & 2.0043 & 1.8792 & 2.257 \\
\pm 6 & 2.4929 & 2.4284 & 2.756 \\
\pm 7 & 2.9220 & 3.0077 & 3.284 \\
\pm 8 & 3.5061 & 3.5671 & 3.792 \\
\pm 9 & 3.9975 & 4.1606 & 4.291 \\
\pm 10 & 4.4910 & 4.5425 & 4.790 \\
\pm 11 & 5.2269 & 5.2225 & 5.463 \\
\pm 12 & 5.9271 & 6.0085 & 5.965 \\
\pm 13 & 6.4800 & 6.5472 & 6.465 \\
\pm 14 & 7.1298 & 7.2607 & 7.094 \\
\hline
\end{tabular}

TABLE 2: Comparative results for $2 N=28$ elements' linear array.

\begin{tabular}{lccccc}
\hline & \multirow{2}{*}{ SLL } & \multirow{2}{*}{ FNBW } & \multicolumn{4}{c}{ Null depth in dB } \\
& & & $30^{\circ}$ & $32.5^{\circ}$ & $35^{\circ}$ \\
\hline Example 1 $(R=0.05)$ & -18.41 & 8.7 & -163.19 & -100.01 & -186 \\
Example 2 $(R=0.1)$ & -18.39 & 8.6 & -171.77 & -140.42 & -164.82 \\
\hline
\end{tabular}
taken:

For the objective function the following relations were

$$
\text { Cost }=\max \left(\left.\operatorname{AF}(\theta)_{\text {norm }}\right|_{8^{\circ}} ^{90^{\circ}}\right)+\operatorname{AF}\left(20^{\circ}\right)_{\text {norm }} .
$$

Mutual coupling effects were under consideration during the processing. In this experiment, we fixed $R=0.1$. The optimal locations with respect to $\lambda$ obtained by using the provided algorithm are shown in Table 4 together with the results obtained in [23]. 
TABLE 3: Comparison with published results for $2 N=28$ elements optimized with respect to position.

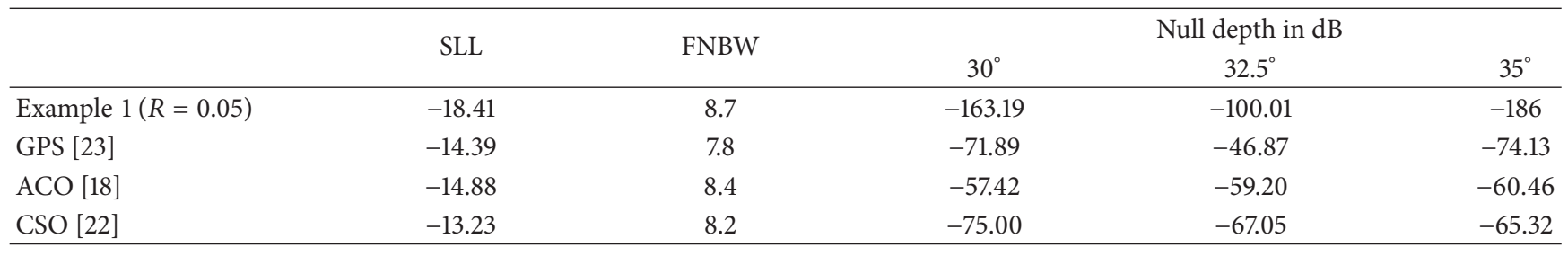

TABLE 4: Element position of the 20 element linear array (normalized with respect to $\lambda$ ).

\begin{tabular}{lccc}
\hline Element & Obtained results & GPS [23] & GA [23] \\
\hline \pm 1 & 0.2387 & 0.25 & 0.264 \\
\pm 2 & 0.7396 & 0.75 & 0.779 \\
\pm 3 & 1.2454 & 1.25 & 1.283 \\
\pm 4 & 1.7750 & 1.787 & 1.840 \\
\pm 5 & 2.2821 & 2.338 & 2.382 \\
\pm 6 & 2.7785 & 2.838 & 2.884 \\
\pm 7 & 3.2473 & 3.338 & 3.389 \\
\pm 8 & 3.7092 & 3.838 & 3.897 \\
\pm 9 & 4.2077 & 4.338 & 4.419 \\
\pm 10 & 4.8180 & 4.990 & 5.079 \\
\hline
\end{tabular}

TABLE 5: Comparison with published results for $2 \mathrm{~N}=20$ elements optimized with respect to position.

\begin{tabular}{lccc}
\hline & SLL & FNBW & Null depth in dB at $20^{\circ}$ \\
\hline Obtained results & -28.5025 & 16.8 & -233.00 \\
GPS [23] & -27.7376 & 16.9 & -61.01 \\
GA [23] & -26.6344 & 16.4 & -80.06 \\
\hline
\end{tabular}

Figure 4 shows a radiation pattern produced by the presented method together with radiation pattern obtained in the work [23]. We can notice that the resulting null is at the position of $20^{\circ}$. In Table $5 \mathrm{SLL}, \mathrm{FNBW}$, and null depth at $\theta_{1}=20^{\circ}$ are shown. We can also notice that SLL obtained by presented method is $-0.8 \mathrm{~dB}$ lower than the examined results obtained in [23]. Radiation pattern obtained with the presented method has a deeper null then the published work [23]. FNBW has a negligible difference.

\section{Conclusion}

In the presented work, we proposed a new algorithm for finding the optimal position of the $5 \mathrm{G} \mathrm{mm}$ wave antenna array elements which minimize side lobe level and placing nulls in desired directions. In both experiments, suppression of SLL was achieved, while nulls were maintained in specified directions and cost function value of presented method converges to the optimum result quickly. Given algorithm provides better results than the compared methods and shows good potential for the $5 \mathrm{G} \mathrm{mm}$ wave antenna array synthesis.

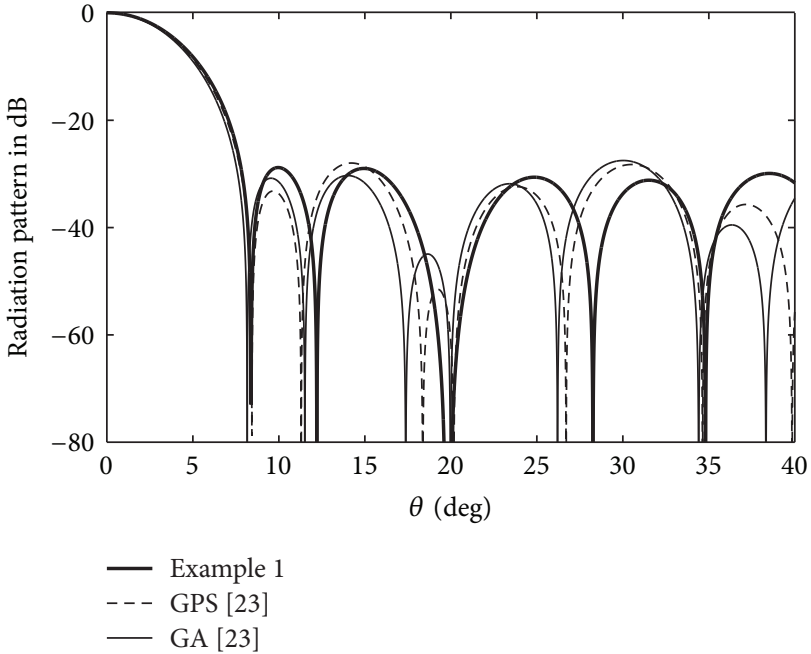

FIgURE 4: The normalized radiation pattern of 20-element linear array.

\section{Conflicts of Interest}

The authors declare that they have no conflicts of interest.

\section{References}

[1] J. Zhang, X. Ge, Q. Li, M. Guizani, and Y. Zhang, "5G millimeter-wave antenna array: design and challenges," IEEE Wireless Communications, pp. 2-8, 2016.

[2] L. Fa-Long and C. J. Zhang, Signal Processing for 5G: Algorithms and Implementations, John Wiley \& Sons, 2016.

[3] S. Rangan, T. S. Rappaport, and E. Erkip, "Millimeter-wave cellular wireless networks: potentials and challenges," Proceedings of the IEEE, vol. 102, no. 3, pp. 366-385, 2014.

[4] M. Park and P. Gopalakrishnan, "Analysis on spatial reuse and interference in $60-\mathrm{GHz}$ wireless networks," IEEE Journal on Selected Areas in Communications, vol. 27, no. 8, pp. 1443-1452, 2009.

[5] S. A. Schelkunoff, "A mathematical theory of linear arrays," The Bell System Technical Journal, vol. 22, no. 1, pp. 80-107, 1943.

[6] C. A. Balanis, Antenna Theory: Analysis and Design, John Wiley \& Sons, San Francisco, Calif, USA, 3rd edition, 2005.

[7] A. D. Bresler, "A new algorithm for calculating the current distributions of Dolph-Chebyshev arrays," IEEE Transactions on Antennas and Propagation, vol. 28, no. 6, pp. 951-952, 1980.

[8] S. J. Orfanidis, Electromagnetic Waves and Antennas, Rutgers University, New Brunswick, NJ, USA, 2014. 
[9] R. S. Eliot, Antenna Theory and Design, Prentice Hall, Upper Saddle River, NJ, USA, 2003.

[10] C. Ramesh and R. Mallikarjuna, "Antenna array synthesis for suppressed side lobe level using evolutionary algorithms," International Journal of Engineering and Innovative Technology (IJEIT), vol. 2, pp. 235-239, 2012.

[11] Y. Cengiz and H. Tokat, "Linear antenna array design with use of genetic, memetic and tabu search optimization algorithms," Progress In Electromagnetics Research C, vol. 1, pp. 63-72, 2008.

[12] G. K. Mahanti, N. Pathak, and P. Mahanti, "Synthesis of thinned linear antenna arrays with fixed sidelobe level using real-coded genetic algorithm," Progress in Electromagnetics Research, vol. 75, pp. 319-328, 2007.

[13] A. Monorchio, S. Genovesi, U. Serra, A. Brizzi, and G. Manara, "A technique to optimize nonuniformly spaced arrays with low sidelobe level by using a genetic algorithm," in Proceedings of the IEEE Antennas and Propagation Society International Symposium, vol. 2, pp. 275-278, Pisa, Italy, July 2005.

[14] K. Güney and A. Akdağli, "Null steering of linear antenna arrays using a modified tabu search algorithm," Progress in Electromagnetics Research, vol. 33, pp. 167-182, 2001.

[15] M. M. Khodier and C. G. Christodoulou, "Linear array geometry synthesis with minimum sidelobe level and null control using particle swarm optimization," IEEE Transactions on Antennas and Propagation, vol. 53, no. 8, pp. 2674-2679, 2005.

[16] M. Rattan, M. S. Patterh, and B. S. Sohi, "Design of a linear array of half wave parallel dipoles using particle swarm optimization," Progress in Electromagnetics Research M, vol. 2, pp. 131-139, 2008.

[17] M. Khodier and M. Al-Aqeel, "Linear and circular array optimization: a study using particle swarm intelligence," Progress In Electromagnetics Research B, vol. 15, pp. 347-373, 2009.

[18] E. Rajo-lglesias and Ó. Quevedo-Teruel, "Linear array synthesis using an ant-colony-optimization-based algorithm," IEEE Antennas and Propagation Magazine, vol. 49, no. 2, pp. 70-79, 2007.

[19] K. N. Abdul Rani, M. F. Abd Malek, and N. Siew-Chin, "Natureinspired cuckoo search algorithm for side lobe suppression in a symmetric linear antenna array," Radioengineering, vol. 21, no. 3, pp. 865-874, 2012.

[20] H. Ahmed and H. Abdelhafid, "Cuckoo search optimization for linear antenna arrays synthesis," Serbian Journal of Electrical Engineering, vol. 10, no. 3, pp. 371-380, 2013.

[21] Z. Rosic, "Antenna array synthesis for suppressed side lobe level using combination of global and local search," International Journal of Engineering and Innovative Technology (IJEIT), vol. 4, no. 6, pp. 58-61, 2014.

[22] L. Pappula and D. Ghosh, "Linear antenna array synthesis using cat swarm optimization," AEU-International Journal of Electronics and Communications, vol. 68, no. 6, pp. 540-549, 2014.

[23] F. Tokan and F. Gunes, "Mutual coupling compensation in nonuniform antenna arrays using inter-element spacing restrictions," Applied Computational Electromagnetics Society Journal, vol. 26, no. 7, pp. 596-602, 2011.

[24] W. Kummer, "Basic array theory," Proceedings of the IEEE, vol. 80, no. 1, pp. 127-140, 1992.

[25] W. L. Stutzman and G. A. Thiele, Antenna Theory and Design, John Wiley \& Sons, New York, NY, USA, 3rd edition, 2012.

[26] M. T. Ma, Theory and Application of Antenna Arrays, John Wiley \& Sons, 1974. 


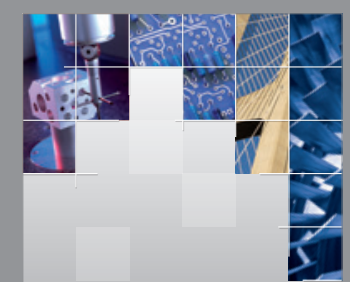

\section{Enfincering}
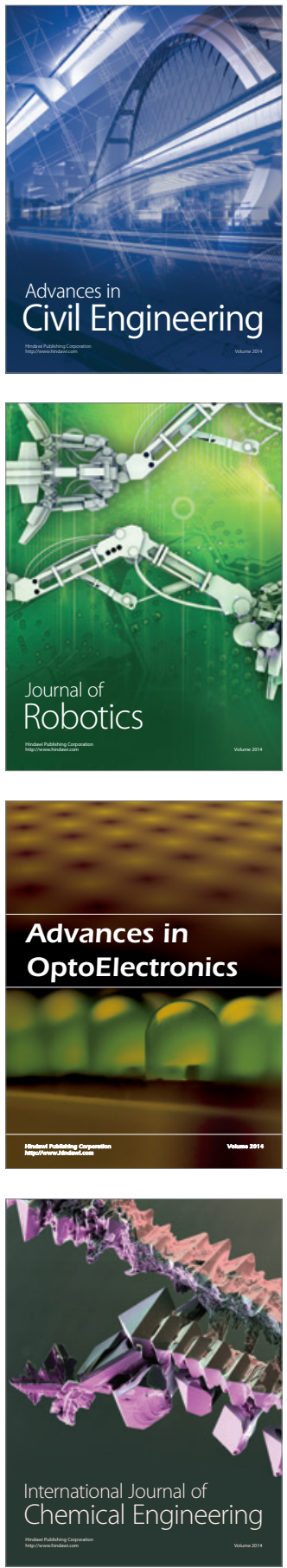

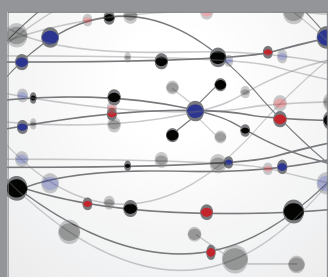

The Scientific World Journal

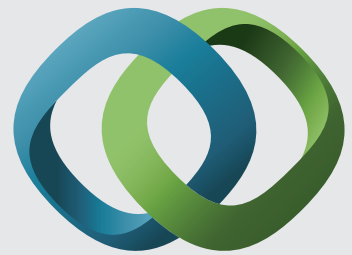

\section{Hindawi}

Submit your manuscripts at

https://www.hindawi.com
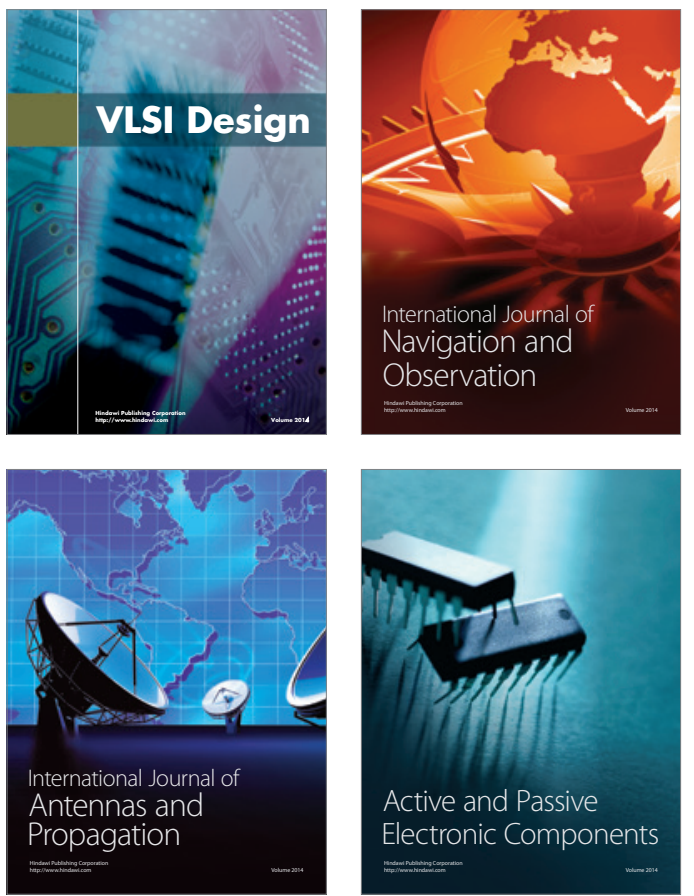
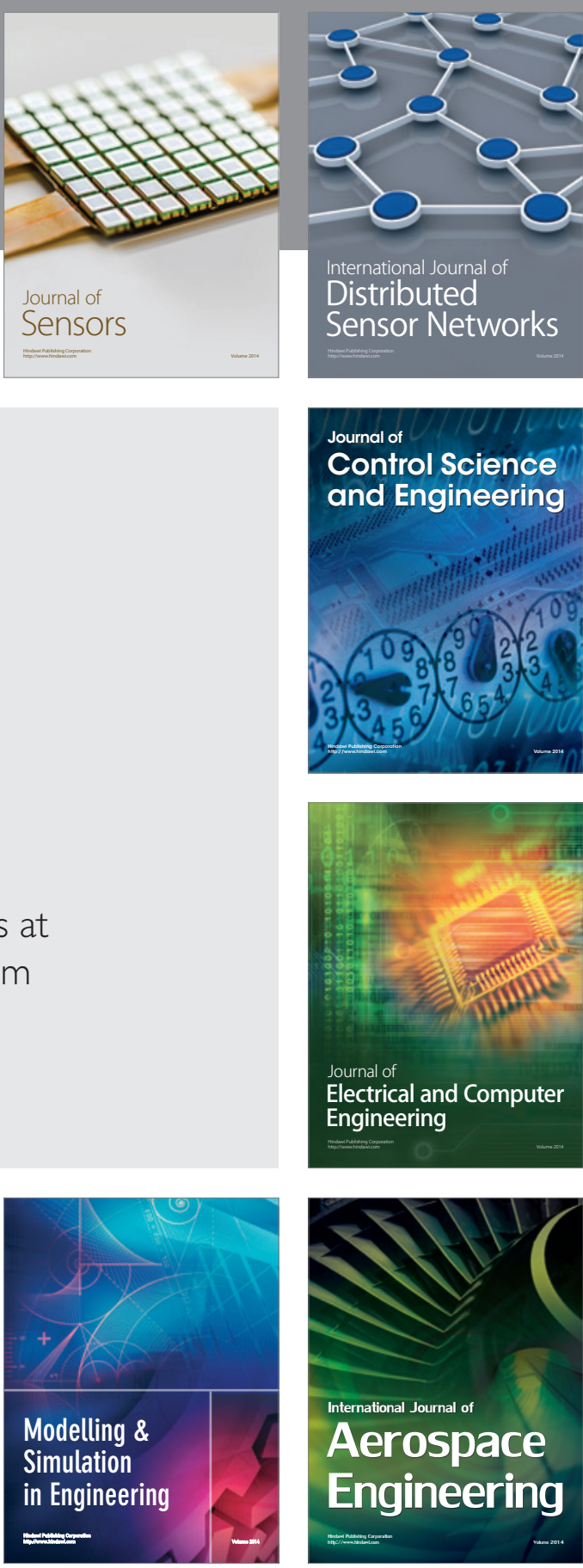

International Journal of

Distributed

Sensor Networks

$-$

Joumal of

Control Science

and Engineering
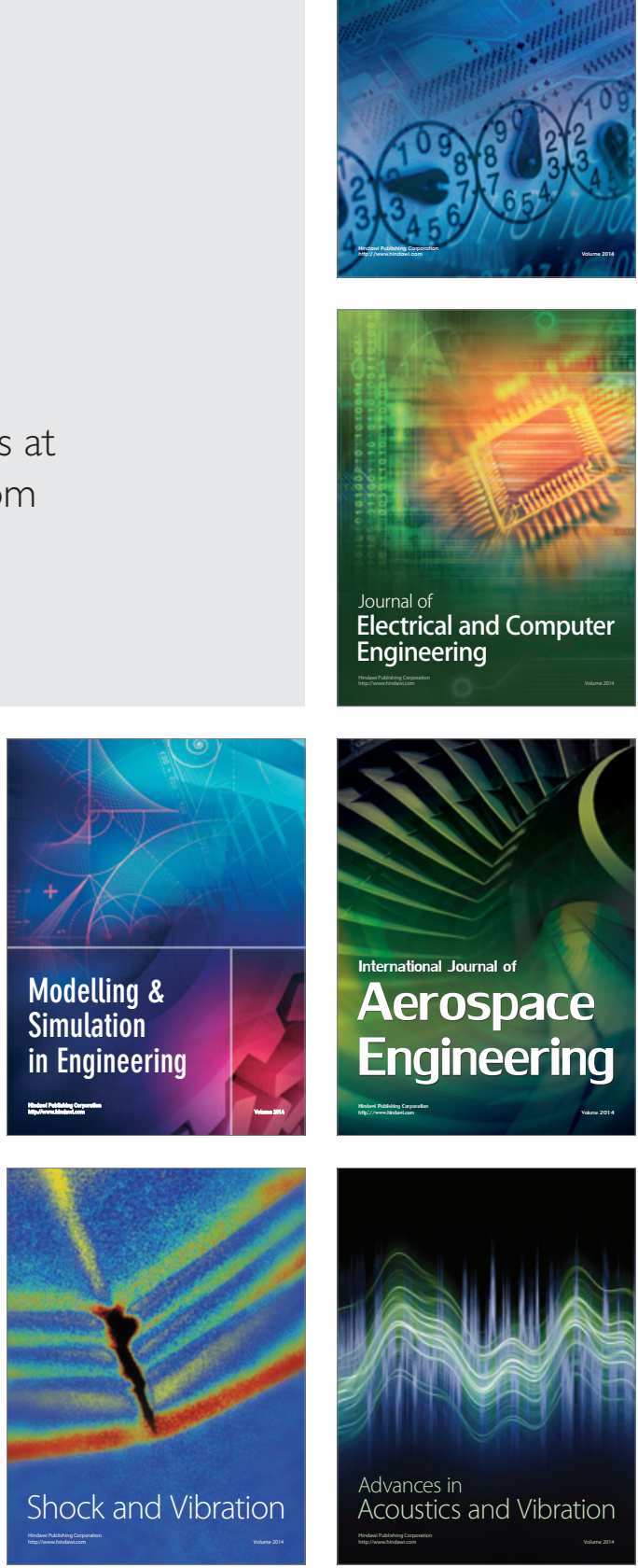